\title{
Papers
}

Explorations into Children's Literature

\section{Gay Subversion: Young Men Seeking Safety in Heterotopic Spaces}

\section{Peter Mountney}

In the early years of the twenty-first century gay-themed texts with teenage protagonists are moving from being an isolated subgenre to becoming a more integrated part of this field of writing and viewing. Even though there is now more visible support for gay adolescents than previously, coming to terms with an emerging gay sexuality and deciding whether or not to declare that sexuality publicly with the inherent risk of marginalisation and loss of family and friends remains central to current gay-themed texts. For boys, the path to manhood can be a journey fraught with challenges but even more so for gay boys who must contend with the forces of 'hegemonic' (heterosexual) masculinities and the pressures to 'do boy' according to socially-sanctioned rules and norms. This article examines the ways the gay protagonists in three Young Adult novels_Leave Myself Behind by Bart Yates (2003), A Time Before Me by Michael Peronne (2005) and Sushi Central by Alasdair Duncan (2003)—and in two filmsPrayers for Bobby (2009) and Geography Club (2013)—seek safety in heterotopic spaces. It is argued that heterotopias can provide safe spaces for the expression of same-sex desire among males, subverting the constraints of hegemonic masculinity and the large spatial sites in which they operate. The trope of 'safe space' can be used as a mechanism to segregate individuals who challenge the heterosexual/homosexual binary under the guise of providing for their safety. However, while safe spaces are mechanisms for the construction of gay identity, they can also generate homophobic retribution. Struggles for visible identities outside of safe spaces can incite violence when gay visibility threatens the normalised landscape.

In Of Other Spaces (1986) Michel Foucault writes of spaces that 'have the curious property of being in relation with all other sites, but in such a way as to suspend, neutralize, or invert 
the set of relations that they happen to designate, mirror or reflect' (p. 24). He identifies two kinds of spaces: utopias, which are sites with no real place, and heterotopias, which are 'something like counter-sites, a kind of effectively enacted utopia' (p. 24). He writes that these heterotopias take varied forms and that 'no one absolutely universal form of heterotopia would be found' (p. 24). Included among some of the forms of heterotopia that Foucault identifies are heterotopias of deviation: 'those in which individuals whose behavior is deviant in relation to the required mean or norm are placed' (p. 25). Foucault cites examples such as rest homes, psychiatric hospitals and prisons. Examples relevant to gay sexuality include gay clubs, gay bars and discos. Other forms of heterotopia identified by Foucault include those with a 'system of opening and closing that both isolates them and makes them penetrable' (p. 26). In general, this kind of heterotopia is not freely available to the public: either the entry is compulsory, as in the case of entering a barracks or a prison, or, to get in, the individual must have certain permissions or make certain gestures, as is required in joining certain clubs and organisations. In the 'safe spaces' analysed in the texts in this article, various strategies are put in place for and by gay males for their socialisation, survival and protection.

\section{Heterotopias and Other Safe Spaces}

For marginalised groups such as gays, personal safety is afforded largely through the creation and maintenance of safe spaces. Such spaces can be metaphorical, as in the notion of the gay 'closet' and the Internet, or they can be actual physical places. The phrase 'being in the closet' generally refers to undisclosed sexual identity, sexual behaviour and gender identity while becoming aware of one's sexual orientation or gender identity and beginning to disclose it to others is described as 'coming out' (Bochenek 2001). A person may be selectively 'out' in some situations or to some people, without generally declaring his or her sexual orientation or gender identity. In the discourse of gay liberation, 'coming out' is seen as an empowering act and an important step in overcoming homophobic attitudes (Rasmussen 2004). However, people resist coming out for a variety of reasons. Pressure not to come out might be associated with a young person's racial or ethnic background, his or her family's religious affiliation, or with family threats regarding the withdrawal of emotional and economic support. Coming out in school settings is particularly problematic because, in that environment, it is very difficult for gays to avoid social isolation, homophobic taunts and even violence. 
There are writers who reject gay liberation’s ‘coming out imperative' (Rasmussen 2004, p. 145) and who argue that, for some, remaining in the closet has advantages. Plummer (1995), for example, argues that secrets can perform 'vital functions' (p. 57) by giving individuals personal autonomy, helping to build identities and affording protection from dangers. Sissela Bok suggests:

To be able to hold back some information about oneself or to channel it and thus influence how one is seen by others gives power ... To have no capacity for secrecy is to be out of control ... it leaves one open to coercion. (1984, pp. 19-20)

The closet offers a space for the practice of same-sex intimate relationships and, in the context of this article, the closet is regarded as a social structure engendered and maintained by the stigma attached to same-sex orientation. For some, the concealment of sexual identity functions as a necessary space for survival against the fear of discrimination and rejection. However, the closet is primarily understood as a disciplinary apparatus, ideologically and legally enforced by a heterosexist culture to justify the exclusion of same-sex orientation from 'real' or legitimate human experience. Eve Sedgwick $(1990,2008)$ describes the closet as 'the defining structure for gay oppression' (2008, p. 71) and she observes that there can be few gay people in whose lives the closet is 'not still a shaping presence' (p. 68). She writes of the 'deadly elasticity of heterosexist presumption' (p. 68) whereby new encounters in different settings - a new school, a new doctor, a new employer-continue to erect new closets requiring 'new draughts and requisitions of secrecy and disclosure' (p. 68). When coming out discourses are privileged, choosing to remain in the closet can be read as an abdication of responsibility, or the act of a disempowered person or someone who refuses to acknowledge his or her same-sex desire. However, people's ability to negotiate their identity continuously is tempered by varying levels of power relating to factors such as age, family background, economic position and race.

As noted previously, safe spaces include physical places, and two Foucauldian notionsthose of dividing practices and heterotopias_-provide a physical manifestation of Sedgwick's metaphorical closet discussed above. In the introduction to The Foucault Reader (1984), Paul Rabinow writes that Foucault regards dividing practices as operating to create social and personal identities through discursive systems and spatial manipulation. Through this notion of dividing practices, the males in the texts who are central to this article can be regarded as a 
group 'given an identity through the dividing practices' (p. 8) which, in effect, sets them apart from heterosexual males. In the binaries that are constituted by Western cultures, to be 'not heterosexual' is to be regarded as 'homosexual', and there are no alternative positions catering for differing degrees of male same-sex desire. Essentially, 'dividing practices' are modes of manipulation that combine forms of 'labelling' with practices of exclusion-often in a spatial sense but always in a social one. The concept of 'spatial dividing practices' is underpinned by Foucault's notion of space as a set of relations which change according to the times, places and persons taking part in the interaction: '[s]pace is fundamental in any form of communal life; space is fundamental in any exercise of power' (Foucault 1984, p. 252).

According to Robert Rom (1998), a 'space' is ‘safe' when individuals and groups understand that their particular expression of identity will not be challenged, they can speak freely, and share their experiences openly. On the other hand, Clair Hemmings and Felicity Grace (1999), while acknowledging that everyone can enter a 'safe space', suggest that such spaces offer the illusion of inclusivity only because acts of entry into these 'safe spaces' are predicated on a process of exclusion from the hetero norm.

These concepts—-heterotopia, safe spaces, the gay closet, and coming out-recur frequently in gay-themed texts. However, these narratives do more than simply tell a story. They are cultural and ideological products and are an important means by which people share experiences and meanings, and seek to make sense of their lives (Stephens, 1992). They are also productive, for within them cultural ideals, values and practices are constructed and reconstructed (Fairclough, 1989; Stephens, 1992). When the depiction of lives and cultures outside the mainstream is considered, the portrayal of uncomfortable differences can be problematic. Gay characters who do not conform to traditional gender roles are frequently targeted with marginalisation and sometimes violence. Many gay-themed texts appear to be based on the assumptions that young adults are, by their nature, homophobic, that their automatic impulse is to fear any disruption to gender conformity, and that 'gay bashing' is 'natural' adolescent behaviour. The texts considered in this article include characters who either question their sexuality, engage in a homosexual act, or are professedly homosexual. Each of the characters follows a trajectory of sexual identity which is characterised by the need to seek solace in safe spaces. 


\section{Fear and the Hegemonic Male}

In this section it is argued that the closet provides a 'protected' real and emotional space, allowing individuals to establish (at least in private) a non-heteronormative subjectivity. Coming out of the closet either voluntarily or forcibly can have very different consequences for the gay subject, ranging from family and community acceptance to total rejection and social isolation. In extreme cases the 'outed' individual can be the target of violence, and may even be killed or choose to commit suicide as a result of such victimisation or inner torment.

Being popular among friends in school is a generally desired status among boys, with popularity serving as a marker of heterosexual status. The social relations of heterosexuality and patriarchy dominate the public space of a school and popularity is defined within that space. Students identified as gay, whether by themselves or by others, cannot be popular in school as public status means being heterosexual or, at least, performing heterosexually (Smith 1998). 'Passing' or pretending to be heterosexual is generally understood in terms of the individual but, in relation to the heterosexual hegemony of the school, it also impacts on the formation of gay groups and openly gay friendships.

As a result of the rigorous policing of sexual and gender norms by heterosexual males, other males who question their same-sex desire can experience confusion and anguish. Noah, the focalising first-person narrator of Leave Myself Behind, reflects on what he sees as the inevitable marginalisation that comes with being gay:

It's not that the idea of being gay bothers me ... It's just that if someone's going to be gay, I'd rather it's somebody else and not me. I’ve seen what happens to gay kids at school and on the streets ... no matter how you slice it, if you're gay you're always on the outside of 'normal' human experience. (Yates 2003, pp. 36-37)

Many closeted gay teenagers live in constant fear of having their same-sex desires made public which can have far-reaching consequences. Noah and his partner, J.D., are confronted with this situation. Despite their efforts to remain closeted, Noah and J.D. are outed by J.D.'s sister who finds them naked in bed. She telephones a friend and the homophobic taunting 
begins at school the next day. Taunts of 'faggot', 'queer', 'homo' and 'buttfucker' are directed at Noah and his friend. George Smith (1998) argues that homophobic abuse is designed to isolate the gay individual by not associating with him or by outright ostracism with harassment building into borderline or actual physical attack. For Noah and J.D., the homophobia culminates with a violent attack which puts them into hospital. The public 'outing' of Noah and J.D. is received differently by the different groups with whom they are associated. The reaction by the school students varies from total homophobic rejection by one group to acceptance by another. Outright rejection is mainly all male focused while acceptance is led by female friends, along with some male friends. Parental reaction is also critical. Noah's mother accepts the fact that he is gay; J.D.'s rejection by his family is absolute - total family alienation culminating in the family's relocation across the country because of the 'shame' occasioned by J.D.'s being outed. Readers are positioned to see how Noah and J.D. struggle for acceptance but they are left with the impression that living with homophobia is an unpleasant reality for gay males.

Being 'normal' in the context of heterosexual hegemony means clearly differentiating what is male and what is female. Characteristics that blur this boundary-effeminacy, not being obviously attracted to the other sex, not being athletic-are socially-constructed markers that suggest a gay subjectivity, and identifying and isolating the gay boy is typically an activity organised within a group of males. Geography Club, the film, is based on Brent Hartinger's (2003) novel of the same name and deals with the emerging gay sexuality of sixteen-year-old Russell Middlebrook. In the novel, Russell is the first-person narrator while in the film, the plot focuses on Russell as the main protagonist who is present in almost every scene. Russell is not effeminate and he is a popular member of his school's football team. His downfall which leads to his being outed to the student body is the fact that he is not attracted to females. Russell, his close friend, Gunnar and two female friends from Goodkind High set out to spend a weekend together at a lake house belonging to the family of one of the females. During the first evening Russell rejects sexual advances from both females, one of whom screams 'faggot' at him. On the following Monday Russell arrives at school to be confronted with hundreds of posters proclaiming ‘Goodkind High’s \#1 Homosexual—Russell Middlebrook.' Russell has no counter to being outed. Sometimes acceptance of a gay subjectivity comes about as a result of a pivotal experience and for Russell his public outing is such an experience. 
Russell's outing has similar consequences to that of Noah and J.D.--homophobic rejection by some but acceptance by others. Without discussing the gay accusation with Russell, his football team unilaterally removes him from the team. It is Kevin Land, the football team's captain, who tells Russell that he is 'off the team'. Kevin's sacking of Russell is ironic because Kevin, too, is gay and it was Kevin who made it possible for Russell to join the football team initially so that, in Kevin's words, they could 'hang out' together without 'people getting suspicious'. Prior to Russell's being outed, rather than publicly appear gay and demonstrate their desire for each other openly, Kevin and Russell choose to 'pass'. In public, they are football buddies; in private they are lovers. Kevin's reassertion of his supposed 'normalcy' in the presence of his football peers reinforces a point made by Bob Pease (2000) that 'heterosexual men try to avoid doing anything that other men might interpret as effeminate or unmanly’ (p. 78). Men fear that any intimacy between men may sully their 'normal' subjectivity.

After being outed, Russell is unable to sit with the football 'jocks' in the cafeteria at lunchtime. With no other student group present that he can identify with, Russell approaches the table where Brian Bund is sitting alone. Brian is not gay. However, his excellent school grades, his cello playing, and his reserved demeanour are sufficient reasons for many of the students to erroneously tag him homosexual. It is surprising that Brian invites Russell to share his table because previously Russell had been part of a 'jock' group of football players who dressed Brian in female attire, applied garish makeup to his face and bundled him into the cafeteria at lunchtime to the amusement of the student body. Homophobic humour is 'targeted at homosexuality, to draw an emotional line between the homosocial male bond and homosexual relationships' (Lyman 1987, p. 156). Homophobic displays consolidate heterosexual masculinities, and Russell's participation in the 'jock' episode involving Brian was complicit with respect to homophobic posturing. Russell's behaviour towards Brian illustrates Smith's (1998) point that 'even students who are gay would keep their distance from 'known homosexuals' at school [thus] the act of passing has the effect of isolating gay students from each other' (p. 328). Kevin's sacking of Russell from the football team is an example of a gay boy (Kevin) remaining closeted when his gay lover (Russell) is outed. For Kevin, the heterosexual façade must remain intact whatever the cost and, in this case, the cost is his relationship with Russell. 
The two texts discussed in this section engage with the consequences for gay males who are forcibly outed. The repercussions of the homophobia inflicted on the characters include isolation, alienation and, in one text, extreme physical violence. Despite the difficulties that Noah, J.D., and Russell are confronted with as a result of their being outed, each character can be read or viewed as a subject who has been transformed over the course of the narrative. At the conclusion of their stories, each appears ready to embrace a gay lifestyle although each is mindful of the limits imposed on their agency by the heteronormative environment in which they live. However, many gay males are not publicly out and it is understandable, then, that in order to experience 'a liveable life' (Butler 2004, p. 39) these males often seek the company of like-minded others in safe environments. The notion of safe space is the focus of the next section.

\section{Gay Safe Spaces}

While hegemonic masculinity is foregrounded in the previous section, its dominance is challenged by the enactment of subversive strategies on the part of the focalising characters in their endeavours to come to terms with their same-sex desires. By creating temporary gay spaces in normally heterosexual environments, gay individuals and gay groups can undermine hegemonic masculinity, at least, for a while. The temporary space functions as a heterotopia-a space that is isolated, yet penetrable but not freely accessible like a public space. The heterotopia that a gay bar provides is an escape from the restrictions, structures and norms that the external heteronormative world seeks to impose on gay subjects (Foucault 1986). However, entering the heterotopia does not signal some end phase of coming out into a gay identity and community. The transition into the new (temporary) social space is tempered by the reality of exiting other (permanent) spaces. The central argument explored in this section is that heterotopias can provide spaces for the expression of same-sex desire among males, subverting the constraints of hegemonic masculinity and challenging heteronormativity and its status as the norm.

The film, Prayers for Bobby, is based on Leroy Aarons' (1995) biography of Mary Griffiths, Bobby's mother. Much of Bobby's story in both the biography and the film is based on Bobby's journals which he began writing when he was fifteen. After revealing his gay sexuality to his brother, Ed, out of concern for Bobby's welfare, Ed outs him to his family. Bobby's coming out clashes strongly with his mother's devout Christian beliefs and he seeks 
the company of gay friends to escape his mother's determined efforts to 'cure' him of his homosexuality.

The Griffith family live in Walnut Creek, California, a city with one gay bar, the Armory, located down a side street, off a main thoroughfare. A visit to the Armory is Bobby's first foray into a gay lifestyle. One evening he drives by the bar but on receiving an encouraging wave from a young man standing outside, he hurriedly drives off. For some gay males, crossing the threshold from the familiar heterosexual world into an unfamiliar gay space can cause anxiety and this is Bobby's initial reaction. He is just beginning to explore his emerging same-sex desire from within the protection of his closet, fully aware that any disclosure of his desires could lead to a homophobic response from 'straight' males intent on maintaining the codes of heteronormativity. As a result of the rigorous policing of sexual and gender norms by heterosexual males, young men who question their same-sex desires can experience confusion and anguish. Later, Bobby overcomes his fears and enters the Armory. Once over the threshold Bobby experiences a whole new world, a gay heterotopia, with its ritualised behaviours and pleasures including dancing, cruising for sex, and alcohol. However, the gay safe spaces that Bobby accesses do not provide him with the escape he seeks from his inner turmoil. Bobby becomes a victim of homophobic intolerance and at age twenty-two, he commits suicide. In Bobby's case, the viewer is positioned to see him as a passive victim, an abject character denied agency even within his own family.

The novel, A Time Before Me is focalised through Mason Hamilton, the first-person narrator. Like Bobby, Mason is introduced to a gay lifestyle by visiting a gay bar. Mason is a highschool student and, in the year after completing school, he works for his aunt at her drag show theatre in the French Quarter in New Orleans. Mason's hometown is Andrew Springs in the State of Mississippi with a population of just over ten thousand residents. Mason admits that he is gay and that as far as he is aware, the only other likely gay person in Andrew Springs is the town's hairdresser. While working part-time at the local ice cream shop, Mason is 'cruised' by an out-of-town visitor, Daniel, who invites Mason to visit a gay bar just outside of the town. Despite being a local, Mason is unaware that such a bar exits. 
Daniel tells Mason that the bar where all of the local gay people go is only accessible 'through word of mouth' (Peronne 2005, p. 82). The bar is in a barn located away from the town down several dirt roads. Daniel says: 'You pay money to just go in and hang out, and you bring your own liquor' (p. 82). The isolated bar provides a heterotopic space for the local gay men to explore their same-sex desires. They can (temporarily) leave their straight 'public' selves beyond the bar's threshold, which forms its boundary with the surrounding heteronormative space. It is the first gay venue of any kind that Mason visits. Over the following weeks Mason and Daniel continue to visit the bar which for both of them provides a gay celebratory space. Mason comments:

Bubba Joe’s [the bar] was the only place where I felt like I could be myself. At Bubba Joe's I could check out cute guys without having to worry about being caught, or for that matter beaten. I could even queen out on the small dance floor if I wanted. I could relax. (p. 89)

Initially, in his hometown, Mason is closeted with limited gay companionship. It is only when he relocates to New Orleans to live with and to work for his gay-friendly aunt that he is able to escape his gay closet and to enjoy a gay lifestyle.

A gay bar is also featured in the novel, Sushi Central, which covers several months in the life of sixteen-year-old Calvin, the first-person narrator. Calvin acknowledges that he is gay and has engaged in sexual activities with other gay males since he was fourteen years old. As a closeted schoolboy living with his parents, Calvin's freedom to live a gay lifestyle is largely confined to gay bars, house parties, private houses, and the Internet where he uses instant messaging and chat rooms to explore further his same-sex desire. Calvin regularly visits a gay bar known as The Beat. As Calvin notes, 'This place is, at various times, a gay club, a meat market, a scene, a place to hang out, dance, to leave your body behind or get messed up with someone else’s’ (p. 85). Entry to The Beat requires ‘certain permission’ (Foucault 1986, p. 26), with 'bouncers' at the door to determine who can enter. In the protected space of the gay bar, the young men engage with an ideology of masculinity based on a notion of 'gay male beauty': 'Everyone ... here is young and good-looking’ (Duncan 2003, p. 95). Their hair has been 'haircutted and dyed to a certain level of alternative/cool' (p. 83) and many wear sleeveless shirts or no shirts to show off their bodies, challenging the notion that overt masculinity is the sole property of heterosexual men. In an endeavour to define themselves as 
a certain kind of masculine subject and to develop their own masculine subjectivity, many young gay males choose to project a body type that is symmetrical, well-groomed and 'devoid of fat' (Drummond 2005, p. 272). The reader is positioned to see Calvin as a subject at ease with his gay sexuality. While constrained by the heteronormative restrictions placed on him by his family and his school environment, Calvin’s gay support network is extensive, which allows him an active and determining presence.

Organised clubs also provide temporary spaces where gays can meet. Russell (Geography Club) is not the only gay student at Goodkind High. Via the Internet he contacts Kevin, the captain of the school football team, and they enter into a clandestine gay relationship. Min, a lesbian student at the school becomes aware of the boys' relationship and she invites them to join with some other students in a gay and lesbian support group that she wants to establish in the school. Initially, none of the group wants to announce their sexuality publicly and so they call themselves the 'Geography Club'. They meet weekly after school in one of the classrooms. The logic in naming their group the Geography Club is the assumption that no straight students will seek to join the group. Thus, they can remain closeted and avoid the trauma of being publicly outed. By creating a temporary gay space in a normally heterosexual environment, the support group is able to operate as a club and challenge the straight space of Goodkind High. Kevin, however, refuses the join the group. He is so committed to his football, to winning a football scholarship, and to maintaining his straight façade that he is prepared to suppress his gay sexuality and remain closeted. No gay space is safe enough for him.

At the conclusion of the film, the Geography Club changes its name to the Gay-Straight Alliance. In order to attend the first meeting Russell has to walk past some of the football team standing menacingly outside the classroom door. One student says to Russell, 'If you go in there, everyone will know'. Russell simply responds, 'That's the point' and he enters the classroom. This incident marks Russell's coming out of the closet as gay but by entering the classroom, which only functions as a temporary safe gay space, viewers are positioned to see how heteronormativity remains a dominant force in the school environment. 
The texts analysed in this section are seen as challenging the assumed normality of heteronormativity and its inherent power structures, exploring this challenge in terms of the heterotopic spaces that non-normative characters access as resistance to the constraints of heteronormativity. In Prayers for Bobby, A Time Before Me, and Sushi Central, the gay bar is the safe space that allows the protagonists to engage with their same-sex desires while in Geography Club a temporary safe space is located in a classroom at Goodkind High. These safe spaces become both sites of resistance and sites of pleasure for the participants. In addition to safe spaces hidden from the active surveillance of hegemonic masculinities, public spaces can also be subverted, albeit on a temporary basis. It is public space that is analysed in the next section.

\section{Subverting Straight Spaces}

Most spaces (social and institutional) in the Western world are hegemonically straight in contrast to gay sites, such as the gay-established and frequented bars, theatres, bathhouses and guest houses which underpin the social organisation of gay 'worlds' and gay relations generally. As noted previously, Foucault describes such gay sites as 'heterotopias of deviation'—places for individuals whose behaviour is deviant in relation to the norm (1986, p. 25). However, gay males also invoke strategies to temporarily appropriate public spaces not identified as 'gay' such as public events including carnivals, public buildings, parks and toilets. The occurrence of sexually transgressive acts in normatively straight spaces subverts these socially 'purified' spaces, highlighting the fact that sexuality and space are indivisible.

In A Time Before Me gay sexuality is explored in and through public spaces, providing additional locations for the protagonists to forge their emerging sexual identities. In the French Quarter in New Orleans on the Labor Day weekend each year, a carnival known as 'Decadence' is held. According to Mikhail Bakhtin (1968), carnival functions as a time of reversal when social conventions are flouted, when normal hierarchies are disrupted and when people give themselves licence to try on new identities, new personas. Public nuditythe open display of breasts, buttocks and genitals-are deviant acts in most social contexts and are officially proscribed even during events such as Decadence (Shrum and Kilburn 1996). Mason is bemused: 
Men were leaning over the balcony dangling beads and chanting, 'Show your dick! Show your dick!’ And people were!

A few 'straight' college guys intrigued by what was going on seemed to have wandered past the invisible wall. I saw a few of them giving in to the Show Your Dick Brigade. Oddly enough, they seemed to be getting off on waving their dicks around for these gay men. (Peronne 2005, p. 126)

The straight males join the gay males in exposing their genitals. They become participants in the carnival activities, knowing that when they withdraw from the gay space they will reenter their heteronormative space without censure. However, for a short time at least, heteronormativity is subverted by the power of the gay community. The carnival enables a temporary heterotopia-one which provides an escape from the world but one that remains within the world. Thus, unlike the ongoing retreat that the gay bar offers, carnival enables a reordering of the social world for only a brief period.

Mason's friend, Daniel, uses his knowledge of gay 'tactics' to disrupt other heteronormative spaces in order to meet men for sex. He explains to Mason that he visited the local library where an 'older guy' reading a newspaper makes eye contact with him. Daniel returns the gaze and provides a follow-on signal by going to the toilet. The man follows and stands at the urinal beside Daniel 'stroking himself' (p. 82). Daniel accepts the man's offer of oral sex but says the library toilet is too public. The man suggests another temporary gay space-his truck outside the library. Daniel accepts the offer and the sex act takes place in the man's truck. The man tells Daniel that he is married, with three children but that 'he has the urge to just suck dick sometimes’ (p. 82). Being married precludes most males from fully embracing a gay lifestyle, so that often their sexual encounters are confined to temporary gay spaces. These temporary heterotopic spaces where gay males can explore their same-sex desire serve to subvert public space and challenge the notion that public space is hegemonically 'straight'.

This section has focussed on the notion that, for a short time at least, heteronormativity can be subverted by the power of the gay community. Public events and public places can be sites for a brief reordering of the social world when the divide between gay space and straight space is set aside. However, the gay subject is still the object of the heterosexual gaze. The focus text works to subvert heteronormative constructions by showing readers alternative 
spaces that are non-threatening to the gay males who frequent them. Nevertheless, the restraints imposed on the protagonists demonstrate the ongoing power of heteronormativity. The next section continues with the concept of 'space' with Foucault's (1986) notion being central to the analysis. However, the focus shifts from the 'real' world to the 'inner-world' of the drug user.

\section{Drugs, Space and Sociality}

In addition to physical or 'real' spaces, drugs may also be regarded as producing heterotopic spaces as their 'othering' effects often produce marginal or ambiguous states. Many drug experiences facilitate being outside oneself ('out of it'), 'lost in the sensual stimulus of a particular space' (Slavin 2004, p. 289). Sean Slavin (2004) argues that drugs and drug spaces trouble notions of sociality or space as fixed or hierarchical, making any simple binary between the social and the asocial in this context untenable. This unsettling of social ordering supports its heterotopian possibilities.

Drugs and casual sex are central features in the lives of the key characters in Sushi Central. On one occasion during a visit to a gay bar Calvin is offered an ecstasy tablet. As Calvin's drug begins to take effect, he says:

But whatever it was that Anthony gave me is starting to take hold and I'm reading way too much significance into everything and it's disturbing me and I don't want to be here anymore, and there's a drink sitting near Lawrence, fizzy, cathode red, and he ignores the straw sticking out of it and takes a huge chug from the glass even though I don't think it's his and Adam and Ben are still talking, and Adam's fucked everyone, everyone, and I don't want to be around this just now. I want to be dancing. I want to be with Anthony. (Duncan 2003, p. 97-98)

Calvin enters a space of his own. On the dance floor, Calvin says: 'I don't know how long we've been here ... he's kissing me again ... I'm pleading for him to fuck me; like seriously, right here on the dance floor' (pp. 98-99). After leaving the bar, the boys take a taxi back to Anthony's house and in the taxi Anthony kisses Calvin. Calvin is sufficiently clear-headed to note the reaction of the Pakistani taxi driver who was watching them. The characters have left their protected space in The Beat and have re-entered public space where displays of samesex affection are proscribed in a heteronormative space. Calvin anticipates a homophobic 
reaction from the driver, but he says: 'I'm so wiped out at his point it doesn't really matter' (p. 101). They reach Anthony's house without incident and as Anthony's parents are away, the house, which is normally a heteronormative space, becomes a temporary heterotopia for the two gay males to engage in sex and spend the night together.

In this section the analysis has moved from a consideration of heterotopias as physical or 'real' spaces to a conceptualisation of them as metaphorical 'drug spaces'. Drug experiences are a significant element in the production of sociality that includes a range of activities such as dancing, socialisation, and sex. In Sushi Central in a drug-induced 'space', Calvin experiences each of these elements.

\section{Cyberspace: A virtual heterotopia}

The focus of the analysis to this point has centred on the interactions of characters in a faceto-face context. However, cyberspace is a communication space that exists as a heterotopia providing virtual meeting places for gay and straight individuals. Through use of chat rooms, instant messaging and other utilities, the Internet gives marginalised individuals opportunities to create or redefine their identities through a constant stream of discourse. With the Internet they find a space or heterotopia in which to write new narratives for their lives and (re)integrate themselves into a virtual world. For gay males whose voices and bodies are largely erased by the culture of hegemonic masculinity, the Internet allows the 'illusion of unfettered visibility and agency in the Internet's virtual 'communities', (Harrison 2010, p. 288). The Internet appears to make it safe to do or simulate online what so many people who are gay or who are questioning their sexuality cannot do in the 'real' world. However, the precarious nature of the Internet and its invisible surveillance connect this heterotopia to the controls and actions that can work against its utopian promise of escape. The illusion of freedom from constraints is similar to the drug-induced feelings of no inhibitions.

Geography Club's opening scene is a chat room exchange between Russell (RUS96) and a chat room buddy (72FINS):

72FINS: I I have these sick shades. Orange frames. I'll wear those. 
RUS96: Cool. I'll be wearing a green shirt with a cartoon lizard on it. Don’t be jealous.

72FINS: Ha. Okay.

RUS96: $\quad$ Look ... it’s really important you don’t tell anyone.

72FINS: $\quad$ For sure. Same here.

RUS96: I mean, I'm not even sure I'm ... you know?

72FINS: $\quad$ Totally get it. I don’t like labels either.

RUS96: $\quad$ Perfect.

Apart from their online chatting, Russell and his chat room friend have not met previously but they agree to meet at a local park, having described to each other how they can be recognised. They literally bump into each other at the park and, to their surprise, each recognises the other as a fellow student from Goodkind High. At that moment neither is prepared to acknowledge their chat room interaction and after a few minutes of small talk they go their separate ways. Corrine Wickens (2007) suggests that young gay males move through a largely linear and developmental process with respect to their emerging sexuality comprising three stages — self-questioning, self-awareness, and self-realisation. Russell's message exchange in the chat room suggests that he is transitioning from questioning his same-sex desire to a growing awareness of a non-heteronormative subjectivity. The mental anguish with respect to secrecy that he is demonstrating at this point reinforces Michael Bronski's (2000) point that 'coming out is essentially a complicated internal process, not a simple public act' (p. 21). Russell is exploring his emerging same-sex desire from within the protection of his closet, fully aware that any disclosure of his desires could lead to a homophobic response from 'straight' males intent on maintaining the codes of heteronormativity.

At age fourteen, Calvin, in Sushi Central, meets Dean, an eighteen-year-old university student, in a chat room and they 'Spent a few very late nights chatting about movies and bands and guys we'd like to fuck' (Duncan 2003, p. 62). Language is the linchpin that connects bodies to their online identities and textual cyberspace facilitates an exploration of individual sexuality in a seemingly protected environment. Calvin meets another gay male, 
Jeremy, in a chat room. Jeremy sends Calvin a link to naked pictures of himself and another gay male called Anthony. Calvin views the photographs and he is captivated by the photograph of Anthony:

'I can’t deal with it. I mean I fucking freak out for a few minutes ... I'm freaking for two reasons ... The fact that the brunette boy [Anthony] is so good-looking ... The fact that the brunette boy looks so much like me'. (p. 31)

In a virtual space created by the Internet, Calvin becomes fascinated by the image of the 'brunette boy' and he says 'How strangely typical is it that the first person I would pick to get seriously obsessed with is some boy who happens to be on the net?' (p. 59). Calvin subsequently meets Anthony and they enter into a physical relationship which lasts a few months, but after an initial good period Calvin comes to the decision that: 'The real Anthony and the Anthony who existed in my head were two entirely different people' (p. 251). Calvin uses the Internet to explore his same-sex feelings on the way to a full(er) embrace of his sexuality. However, the fantasy that he builds around Anthony in a virtual space cannot be sustained in a 'real' space.

The anonymity that the Internet can provide for gay characters has been the focus in this section. Both Russell in Geography Club and Calvin in Sushi Central initially explore their developing same-sex desires from the protection of a virtual heterotopia away from the active surveillance of hegemonic masculinities. In due course, their experiences in their virtual heterotopias lead them to more fully embrace their emerging gay sexuality, progressing through self-awareness to full self-realisation.

As might be expected in coming-out stories, the gay characters in the texts analysed in this article experience considerable angst in the process, especially Noah in Leave Myself Behind and Russell in Geography Club where the gay characters' coming out happens because they are outed publicly. In A Time Before $M e$, it is public space that provides locations for the major characters to forge their sexual identities although the text also offers a variety of heterotopias where the characters can explore their sexuality in safe spaces. In Sushi Central, drugs and casual sex are central features in the major characters' lives that unfold in a variety of 'real' spaces as well as in the virtual space of the Internet. The Internet is also a feature of Geography Club. It is the Internet that provides marginalised individuals with opportunities 
to create or redefine their identities through a constant stream of discourse, to do or simulate online what so many people who are gay cannot do in the 'real world'. In Prayers for Bobby, alienated from his close-knit family, Bobby seeks solace in the heterotopias of the gay community but to no avail. His depression tragically overwhelms him and he commits suicide.

Heterotopias provide individuals with an escape not only from the world, but also from the norms and structures that constrain them and their desires to develop their individual subjectivities. The heterotopias explored in this article offer safe spaces for males exploring and performing a gay subjectivity in contexts constrained by heteronormativity. While the dominant position that heteronormativity occupies can render acts of subversion ineffective, ongoing resistance will continue to characterise non-hegemonic masculinities.

\section{Works Cited}

Aarons, Leroy (1995) Prayers For Bobby. New York: Harper One.

Bakhtin, Mikhail (1968) Rabelais. Cambridge: MIT University Press.

Bochenek, Michael (2001) Hatred in the Hallways: Violence and Discrimination Against Lesbian, Gay, Bisexual, and Transgender Students in U.S. Schools. New York: Human Rights Watch.

Bok, Sissela (1984) Secrets. New York: Vintage.

Bronski, Michael (2000) 'Positive Images and the Coming Out Film: The Art and Politics of Gay and Lesbian Cinema’. Cineaste 26 (1): 20-26.

Butler, Judith (2004) Undoing Gender. New York: Routledge.

Drummond, Murray (2005) 'Men’s Bodies: Listening to the Voices of Young Gay Men'. Men and Masculinities 7 (3): 270-290.

Duncan, Alasdair (2003) Sushi Central. St Lucia, Qld: University of Queensland Press.

Fairclough, Norman (1989) Language and Power. London: Longman.

Foucault, Michel (1984) 'Space, Knowledge and Power.' In P. Rabinow (ed) The Foucault Reader. London: Penguin, pp. 239-256.

Foucault, Michel (1986) ‘Of Other Spaces’. Diacritics 16 (1): 22-27.

Geography Club (2013) DVD recording, Huffington Pictures. 
Harrison, Douglas (2010) 'No Body There: Notes on the Queer Migration to Cyberspace'. The Journal of Popular Culture 43 (2): 286-308.

Hartinger, Brent (2003) Geography Club. New York: HarperTempest.

Hemmings, Clare and Grace, Felicity (1999) 'Stretching Queer Boundaries: An Introduction'. Sexualities 2 (4): 387-396.

Kimmel, Michael (ed) (1987) Changing Men. London: Sage Publications.

Lyman, P (1987) 'The Fraternal Bond As a Joking Relationship: A Case Study of the Role of Sexist Jokes in Male Group Bonding.’ In M. Kimmel (ed) Changing Men. London: Sage Publications, pp. 148-164.

Pease, Bob (2000) Recreating Men: Postmodern Masculinity Politics. London: Sage Publications.

Peronne, Michael (2005) A Time Before Me. New York: iUniverse.

Plummer, Ken (1995) Telling Sexual Stories. London: Routledge.

Prayers For Bobby (2009) DVD recording. Once Upon a Time Films.

Rasmussen, Mary (2004) 'Safety and Subversion: The Production of Sexualities and Genders in School Spaces.' In M. Rasmussen, E. Rofes, and S. Talburt, S. (eds) Youth and Sexualities: Pleasure, Subversion, and Insubordination In and Out of Schools, pp.131-152. New York: Palgrave Macmillan.

Rasmussen, Mary, Rofes, Eric. and Talburt, Susan (eds) (2004) Youth and Sexualities: Pleasure, Subversion, and Insubordination In and Out of Schools. New York: Palgave Macmillan.

Rabinow, Paul (ed) (1984) The Foucault Reader. London: Penguin.

Rom, Robert Boost (1998) 'Safe Spaces: Reflections on an Educational Metaphor'. Journal of Curriculum Studies, 30 (4): 397-408.

Sedgwick, Eve (1990, 2008) Epistemology of the Closet. Berkeley: University of California Press.

Slavin, Sean (2004) 'Drugs, Space and Sociality in a Gay Nightclub in Sydney'. Journal of Contemporary Ethnography 33 (3): 265-295.

Shrum, Wesley and Kilburn, John (1996) 'Ritual Disrobement at Mardi Gras: Ceremonial Exchange and Moral Order’. Social Forces 75 (2): 423-458.

Smith, George (1998) 'The Ideology of 'Fag': The School Experience of Gay Students'. The Sociological Quarterly 39 (2): 309-335.

Stevens, John (1992) Language and Ideology. London: Longman.

Wickens, Corrine (2007) Queering Young Adult Literature: Examining Sexual Minorities in Contemporary Realistic Fiction 2000-2005. Thesis, Texas A and M University.

Yates, Bart (2003) Leave Myself Behind. New York: Kensington Books. 


\section{Biographical note}

Peter Mountney's research interests include masculinity, gender studies, queer theory, film and new media. For his doctoral thesis, undertaken at the Queensland University of Technology, he researched same-sex desire and hegemonic masculinity in contemporary Young Adult fiction. His current research at the University of the Sunshine Coast focuses on filmic representations of gay son-father relationships. 